\title{
Phonological Development in Young Bilinguals: Clinical Implications
}

\author{
Cynthia Core, Ph.D., CCC-SLP' ${ }^{1}$ and Chiara Scarpelli, B.A. ${ }^{1}$
}

\section{ABSTRACT}

This article reviews recent research on bilingual phonological development and describes the nature of bilingual phonology, focusing on characteristics of cross-linguistic influence on bilingual phonological abilities. There is evidence of positive and negative transfer (acceleration and deceleration) on children's phonological abilities. Several methodological issues limit the ability to generalize findings from previous research to larger groups of bilingual children (e.g., small sample size, lack of consideration of age of acquisition of each language, and language abilities of the participants). Sources of heterogeneity in language development are presented and discussed. Phonological abilities are related to language abilities in bilingual first language learners of English and Spanish. Empirical evidence from research in our laboratory supports this claim. We discuss implications of research findings and limitations for future research and clinical practice. We provide specific recommendations for bilingual research and for clinical assessment of young bilingual children.

KEYWORDS: Bilingual, phonology, speech, assessment, language

Learning Outcomes: As a result of this activity, the reader will be able to (1) discuss sources of heterogeneity in bilingual language and phonology; (2) summarize effects of language proficiency and experience on bilingual phonology; and (3) describe implications of language experience on clinical assessment.

Speech-language pathologists (SLPs) face a considerable challenge in accurately differentiating between speech and language disorders and speech and language differences when working with bilingual children. ${ }^{1}$ According to annual estimates of population change, the
${ }^{1}$ Department of Speech and Hearing Science, the George Washington University, Washington, District of Columbia.

Address for correspondence: Cynthia Core, Ph.D., CCC-SLP, Department of Speech and Hearing Sciences, the George Washington University, Washington, DC 20052 (e-mail: core@gwu.edu).
Language Impairment in Bilingual Children: From Theory to Practice; Guest Editor, Aquiles Iglesias, Ph.D.

Semin Speech Lang 2015;36:100-108. Copyright (C) 2015 by Thieme Medical Publishers, Inc., 333 Seventh Avenue, New York, NY 10001, USA. Tel: +1(212) 5844662.

DOI: http://dx.doi.org/10.1055/s-0035-1549105.

ISSN 0734-0478. 
Hispanic population is the fastest-growing minority group in the United States. ${ }^{2}$ Furthermore, children with speech sound disorders make up the majority of the caseloads of school-based SLPs. ${ }^{3}$ From this we can infer that many school-based SLPs must assess and potentially treat bilingual children with suspected speech sound disorders, and they are especially likely to encounter Spanish- and English-speaking bilingual children on their caseloads. To accurately diagnose speech sound disorders in bilingual children, we first need to understand the time course and patterns of bilingual phonological development and to differentiate characteristics of normal bilingual development from atypical or delayed development in bilingual children.

Phonology has been studied less extensively than other areas of bilingual development. Although several studies examine the framework of phonological abilities of bilingual children, few studies have examined the development of phonological abilities over time in bilingual children or identified error types or patterns that indicate atypical phonological development in bilingual children. Hambly and colleagues published a systematic review of bilingual speech production and found that of 66 studies reviewed, only 15 studies used case controls or cohort observations. ${ }^{4}$ Many studies were single case studies that focused on interaction patterns between languages. Longitudinal studies were most commonly of single subjects rather than groups of children, limiting knowledge of broader developmental patterns. There were only a few studies with large samples of bilingual children, and those are for Pakistani- and English-, Welsh- and English-, and Maltese- and English-speaking children. ${ }^{5-7}$ Many studies of bilingual phonology focus on narrow aspects of production, such as acquisition of specific sounds, ${ }^{5}$ prosodic patterns, ${ }^{8}$ and interaction patterns between languages ${ }^{9}$ rather than longitudinal patterns of typical or atypical development. With only a few exceptions, most studies of bilingual phonology have focused on bilingual speakers of English and Spanish, but even so, we have little information about typical phonological development in Spanish- and English-speaking children, and even less for children who speak other language pairs.

SLPs report that they have limited understanding of how to differentiate language difference from language disorder in bilingual children. ${ }^{10}$ Several studies have shown that most school-based SLPs are monolingual speakers of English who rely on English measures to evaluate bilingual children, even if English is not the child's stronger language. ${ }^{11-13}$ The lack of knowledge about bilingual speech sound development may lead to fewer than expected bilingual children with speech sound disorders receiving services as a result. ${ }^{14,15} \mathrm{We}$ do not know the effects of using single-language assessments to evaluate children's phonological knowledge. However, there is considerable evidence that evaluating bilingual children in only one of their spoken languages and interpreting results with respect to monolingual norms can lead to overidentification of language disorders because bilingual children's language abilities in one language fall well below those of their monolingual peers. ${ }^{16-18}$

\section{THE NATURE OF BILINGUAL PHONOLOGY}

Current research on phonological development seems to agree that children have two separate phonological systems that interact. ${ }^{4,19-21}$ Interaction is caused by cross-linguistic transfer and can yield both positive and negative effects, referred to in some studies as acceleration and deceleration. ${ }^{20,22}$ Acceleration refers to positive transfer of cross-linguistic knowledge, for example, early acquisition of a phonological structure by bilingual children compared with monolingual children acquiring the same structure. Deceleration refers to negative cross-linguistic transfer, for example, slowed learning of aspects of phonology by bilingual children compared with monolingual children, and sometimes is referred to as a "delay in acquisition.” A third possibility also exists: transfer can be bidirectional, with both positive and negative transfer occurring in the same child. Transfer of knowledge or abilities can influence the rate of acquisition of the sound system of a language relative to monolingual speakers of the language, and transfer of abilities across languages 
can also interact with other developmental patterns, resulting in a wide range of phonological abilities in bilingual children.

Some aspects of phonology may be learned earlier for bilingual children than for monolingual children due to positive transfer of phonological knowledge. For example, Kehoe and associates and Lleó and colleagues examined the production of coda consonants in SpanishGerman bilingual children and found a higher rate of coda production in the Spanish productions of bilinguals than in those of Spanish monolinguals. ${ }^{22,23}$ They hypothesized that the presence of coda consonants in German facilitated bilingual children's awareness of and ability to produce those sounds relative to monolingual Spanish-speaking children who had less experience with coda consonants. Goldstein and Bunta reported positive transfer in 10 bilingual children (mean age 5;6). ${ }^{24}$ Bilingual children with nativelike proficiency in English outperformed monolingual children on several measures of consonant and vowel accuracy.

Fabiano-Smith and Goldstein proposed another form of acceleration, characterized by bilingual children performing on par with monolingual children despite the task of learning two languages. ${ }^{19}$ Their proposal was supported by evidence that 8 Spanish-dominant bilingual children in their study had some phonological abilities on par with monolingual children, despite having less overall experience with that language. There are few studies of bilingual phonology that directly compare monolingual and bilingual children, but many of those find no difference in abilities between the two groups. MacLeod and colleagues found that French-English bilingual, first languagelearning children kept pace with monolinguals at 18 and 36 months on multiple measures of phonology. ${ }^{25}$ Goldstein et al found that bilingual children performed similarly to monolingual peers in both languages for several measures of phonology including segmental and syllabic accuracy and percentage of occurrence of phonological patterns. ${ }^{26}$ Their sample included both simultaneous and sequential learners of English. Goldstein and colleagues found that 4- and 5-year-old Spanish-English bilingual children produced consonants, sound classes, and phonological patterns with similar levels of accuracy as children who were dominant speakers of English and Spanish. ${ }^{26,27}$

Other studies have demonstrated that bilingual children acquire phonological skills at a slower rate than their monolingual peers. This has led researchers to conclude that there is negative transfer or deceleration in learning for bilingual children. ${ }^{8,20,21,28}$ GildersleeveNeumann and colleagues examined the English phonological skills of 11 typically developing, bilingual (English-Spanish) 3-year-olds. ${ }^{20}$ Bilingual children in their study had lower intelligibility ratings, made more consonant and vowel errors, and produced more uncommon error patterns than monolingual English speakers of the same age. Bunta and colleagues found that Spanish- and English-speaking monolingual children were significantly better than bilingual children on production of consonant accuracy measures and described this as decelerated abilities in Spanish. ${ }^{8}$ Fabiano-Smith and Goldstein found that monolingual Spanishspeaking children were more accurate than bilingual children on measures of consonant accuracy, but no differences were found between bilingual children and English monolingual speaking peers. ${ }^{19}$ Gildersleeve et al found that bilingual children used error patterns from one language in their other language, leading to unusual error patterns, which resulted in a form of negative transfer. ${ }^{29}$ Finally, a few studies provide evidence of bidirectional influence of the two languages for bilingual children. ${ }^{19,30}$

Several methodological issues of existing studies affect the ability to determine whether bilingual children perform differently from their monolingual peers on phonology measures. Most studies did not systematically consider factors such as age of exposure to each language, relative amount of exposure to each language, use patterns for each language, or proficiency in each language. Age of acquisition of each language and relative amount of exposure to or experience with each language are particularly important measures that are often overlooked in studies of bilingual phonology but could potentially account for much of the variation in bilingual phonological abilities. For example, bilingual first language learners (simultaneous bilinguals) are likely to have differing patterns of phonological development from 
sequential dual language learners because sequential learners will have at least partially acquired one system as they begin to acquire their second language, and they may transfer phonological knowledge and production abilities from the first language to the second language. Morrow and colleagues found that age of acquisition to English and length of exposure to English were important predictors in the phonological abilities of English language learners from a variety of language backgrounds. ${ }^{30}$ Children in their study who achieved the highest levels of English accuracy started learning English earlier and had more years of experience with English than other children in the study.

Most studies of bilingual phonology have very small sample sizes, and given the heterogeneity in bilingual experience and language outcomes, these studies do not allow for generalizability of results. Some studies compared children's performance to speech sound norms rather than to socioeconomic status (SES)-matched peer groups. Additional influences on bilingual phonological development might come from the typologies of languages being acquired and the degree of overlap of phonological structures of each language. Other factors, such as exposure to native or nonnative input, might also affect phonological learning. However, to date research has not systematically evaluated the role of these variables on phonological development in bilingual children.

\section{THE ROLE OF LANGUAGE PROFICIENCY AND LANGUAGE EXPERIENCE IN BILINGUAL PHONOLOGY}

There are several reasons to believe that bilingual children's phonological abilities would be related to their proficiency in the same language. Some theories of phonological development propose that phonology is influenced by learning the lexicon and emerges out of lexical development. $^{32-35}$ Other theories propose that phonological abilities, particularly phonological memory, are an innate ability that children use to build their language skills. ${ }^{36}$ Research with monolingual children has shown commensurate abilities between phonology and vocabulary for late talkers, children with specific language impairment, and precocious word learners. ${ }^{37-41}$ In studies of bilingual children, researchers have identified relationships between vocabulary and grammatical ability in bilingual children and between grammatical ability and phonological ability. ${ }^{42-44}$

Yet few studies of bilingual phonology have systematically considered language abilities. In a group of 83 Welsh-English bilingual children (ages 2;6 to 5;0), Ball and colleagues found that the production of the trilled $/ \mathrm{r} / \mathrm{showed}$ different patterns of acquisition depending on language experience, in that Welsh-dominant children acquired the trill earlier than their peers who were English-dominant. ${ }^{5}$ In a study of 15 typically developing 5-year-olds (five predominantly English-speaking, five predominantly Spanish-speaking, and five SpanishEnglish bilingual children), Goldstein and colleagues found no significant correlations between parent estimate of children's use (output) of a language and phonological skills in the same language. ${ }^{26}$ However, in a larger group $(n=50)$ of Spanish-English bilingual children between the ages of 4;3 and 7;1, Goldstein and colleagues found that parent estimates of child language use and proficiency as well as a direct measure of proficiency (mean length of utterance (MLU) in words) predicted children's segmental accuracy in both languages. ${ }^{44}$

Research in our laboratory has found that language and phonological abilities are related in bilingual first language learners of English and Spanish (simultaneous bilinguals). We found this to be true for production of sounds in real words for each language and for production of nonwords in each language. Understanding how phonological and language abilities develop together can give insight into cross-linguistic transfer of phonological abilities and may help explain some of the variation in bilingual phonology. Children in our studies are all bilingual first language learners of English and Spanish living in South Florida. Our main findings are summarized below.

1. There are language specific relationships between phonological abilities and language abilities. Parra and colleagues found that accuracy of production of English-like and 
Spanish-like nonword stimuli (a measure of phonological memory) was uniquely related to vocabulary and grammar in the same language for children from 22 to 30 months. ${ }^{45}$ During the same age range, we found language-specific relationships of production of real words to vocabulary size in each language, but we did not find relations of phonology and vocabulary across languages. ${ }^{46}$ In another sample of 57 30month-old bilingual children, English word production accuracy was related to English vocabulary but not Spanish vocabulary and production of Spanish words related to Spanish vocabulary but not to English vocabulary. These effects held even when controlling for amount of exposure to each language. ${ }^{47}$

2. Relative exposure to each language affects phonological abilities in that language. ${ }^{45}$ For our youngest participants at 22 and 30 months, the relative amount of exposure to English was uniquely related to Englishlike nonword repetition accuracy, and exposure to Spanish was uniquely related to Spanish-like nonword repetition accuracy. We did not continue to see these effects in analyses of data for children ages 30 and 48 months, though relative amount of exposure to each language was related to vocabulary size for both languages and vocabulary size was related to phonological abilities. ${ }^{47,48}$

3. Differences in production accuracy between English and Spanish abilities reflect similar differences in language proficiency. Children with larger English vocabularies had better speech production abilities for English words and English-like nonword stimuli than children with smaller English vocabularies at 22, 30, and 48 months of age. ${ }^{46-48}$ The same findings were true for Spanish vocabulary size and phonological abilities. At 48 months, children's English production accuracy was greater than their Spanish on average, and they were also more proficient in English and had greater exposure to English on average, suggesting that phonological abilities are tied to language abilities. ${ }^{48}$ Another indicator of the relationship between phonological accuracy and language proficiency is that the types of errors children made differed by whether they had large or small vocabularies in the language. For example, 30-month-old children with large English vocabularies were less likely to delete initial consonants than children with small English vocabularies. ${ }^{47}$

4. Production abilities were related across languages at 30 and 48 months. Both real word and nonword accuracy was related across languages for bilingual children, suggesting shared underlying abilities for phonology. By 48 months, children were highly accurate at producing words in both languages, despite continuing differences in proficiency and amount of exposure to each language. ${ }^{48}$ Mean percent consonants correct for English was $90 \%$ and was $87 \%$ for Spanish. Both vocabulary size and earlier speech production contributed significantly to phonology outcomes at 48 months and together accounted for $40 \%$ of the variation in children's phonological abilities.

From these findings, we conclude that there are both language-general and language-specific relations between phonology and other language abilities. Relationships between pronunciation (phonology) and vocabulary size within a language but not across languages suggest that children's phonological abilities and word learning develop together. It is likely that these relationships are bidirectional, with phonology and language interacting with each other and with amount of exposure to each language as a bilingual child's abilities develop. ${ }^{45}$ Although English and Spanish share many sounds and have relatively similar phonological (sound) systems, the language-specific relations between language and phonology confirm that phonological development is specific to each language. However, the relationships of production accuracy across languages suggest that sound learning also involves more general or shared abilities, such as auditory memory capacity or speech motor production abilities.

\section{CLINICAL IMPLICATIONS}

The state of knowledge about bilingual phonological development offers several implications 
for research and clinical assessment. First, a child's language experience and language proficiency play an important role in his or her phonological abilities. For example, a simultaneous bilingual child who hears mostly Spanish at home and learns English once he or she begins school will have poor English abilities relative to monolingual children (in particular) at school entry. If the child has a small English vocabulary or low proficiency in English, then speech sound accuracy as measured by standardized tests of articulation would be expected to be lower than a simultaneous bilingual child who hears both English and Spanish at home and has stronger language abilities in English. In another example, if a bilingual child has good proficiency in English as measured by standardized tests but has very poor speech production abilities in English, SLPs can be much more confident in diagnosing a speech sound disorder.

There are few standardized, norm-referenced tests of speech (phonological and/or articulation) ability for bilingual children. ${ }^{49}$ There are some limitations to using the tests and interpreting results. For tests that have published norms (Bilingual English-Spanish Assessment ${ }^{50}$ and the Contextual Probes of Articulation Competence-Spanish ${ }^{51}$ ), the norms do not differentiate among children by age of acquisition of each language, relative exposure to each language, or proficiency level in each language. Thus, clinicians must carefully consider a child's age, language proficiency and age of acquisition of each language when interpreting a child's score relative to the norms for the child's age. A child raised simultaneously bilingual in the United States would be expected to perform in the average range for his age for English but not necessarily for Spanish, depending on his experience with Spanish. However, if the child is an older child (e.g., 5 years old) and just beginning to learn English, he may be expected to perform in the average range for Spanish but not English. Oder children who have been speaking English longer are more likely to score in the average range on standardized tests and to achieve accuracy levels on par with their monolingual peers. Similarly, simultaneous bilinguals seem more likely to have speech skills similar to monolingual speakers. Scores below the average range require careful consideration of factors affecting language experience and proficiency. Other tests are criterion-referenced rather than norm-referenced and provide limited information to help determine clinical status of phonology. Another way SLPs can assess bilingual children on their caseloads is to develop local norms. For example, in communities where bilingual experiences are similar, SLPs could use the available norm-referenced measures to assess typically developing children in their community with similar language experiences and abilities, then identify the typical performance level of children in the community. That would allow SLPs to identify children with atypical development compared with their community peers with similar language experience. This would be particularly useful in communities where SLPs notice below-average performance by a group of children without reason to expect that all of the children have speech sound disorders.

Several studies report on the variability in bilingual speech abilities relative to monolingual children. ${ }^{4}$ But studies have not attempted to sort out the factors that contribute to the heterogeneity of bilingual abilities. Without more data on the interactions between bilingual speech and language development, we cannot easily tell which bilingual children are developing typically for their linguistic experiences and which ones might have delayed or atypical development. This makes assessment of bilingual phonology very difficult. Furthermore, there are likely complex interactions between normal phonological development, development of phonological abilities commensurate with language abilities for each language, and cross-linguistic transfer. Because bilingual children as a group have considerable variation in their language experience from factors such as their relative proficiency in each language, relative amount of input and output in each language, and age at acquiring the second language in the case of nonsimultaneous learners, we can also expect more variability in their phonological abilities. 


\section{CONCLUSION}

Language experience matters for understanding bilingual development. We need to understand how language abilities interact with phonological abilities (speech, phonological awareness and phonological processing). Just as with studies that aim to understand bilingual language development, factors of SES and linguistic experience need to be considered. Studies need to include information on language proficiency and relative balance, as well as variation in language abilities from SES factors, and possibly also from cultural differences. To improve our diagnostic abilities, we need more information about typical phonological development in bilingual children, especially between the ages of 2 and 5 years, and the influence of age of acquisition and relative amount of exposure on phonological abilities.

\section{ACKNOWLEDGEMENTS}

This research was supported by grants to Erika Hoff from the Eunice Kennedy Shriver National Institute of Child Health and Human Development, HD054427, HD060718, HD068421, and by a Luther Rice fellowship to Chiara Scarpelli from the George Washington University.

\section{REFERENCES}

1. De Lamo White C, Jin L. Evaluation of speech and language assessment approaches with bilingual children. Int J Lang Commun Disord 2011; 46(6):613-627

2. United States Census Bureau. Estimates of the Components of Resident Population Change by Race and Hispanic Origin for the United States: April 1, 2010 to July 1, 2013. 2014

3. American Speech-Language-Hearing Association. Schools Survey Report: SLP Caseload Characteristics Trends 1995-2010. 2010

4. Hambly H, Wren Y, McLeod S, Roulstone S. The influence of bilingualism on speech production: a systematic review. Int J Lang Commun Disord 2013;48(1):1-24

5. Ball MJ, Müller N, Munro S. The acquisition of the rhotic consonants by Welsh-English bilingual children. Int J Biling 2001;5:71-86
6. Grech H, Dodd B. Phonological acquisition in Malta: a bilingual language learning context. Int J Biling 2008;12:155-171

7. Stow C, Pert S. Phonological acquisition in bilingual Pakistani heritage children in England. In: Hua S, ed. Phonological Development and Disorders in Children: A Multilingual Perspective. Clevedon, UK: Multilingual Matters; 2006

8. Bunta F, Fabiano-Smith L, Goldstein B, Ingram D. Phonological whole-word measures in 3-yearold bilingual children and their age-matched monolingual peers. Clin Linguist Phon 2009; 23(2):156-175

9. Brice AE, Carson CK, O'Brien JD. Spanish-English articulation and phonology of 4-and 5-yearold preschool children an initial investigation. Comm Disord Q 2009;31:3-14

10. Skahan SM, Watson M, Lof GL. Speech-language pathologists' assessment practices for children with suspected speech sound disorders: results of a national survey. Am J Speech Lang Pathol 2007; 16(3):246-259

11. Caesar LG, Kohler PD. The state of school-based bilingual assessment: actual practice versus recommended guidelines. Lang Speech Hear Serv Sch 2007;38(3):190-200

12. Prezas RF, Hodson BW, Schommer-Aikins M. Phonological assessment and analysis of bilingual preschoolers' Spanish and English word productions. Am J Speech Lang Pathol 2014;23(2): 176-185

13. Williams CJ, McLeod S. Speech-language pathologists' assessment and intervention practices with multilingual children. Int $\mathrm{J}$ Speech-Language Pathol 2012;14(3):292-305

14. Stow C, Dodd B. A survey of bilingual children referred for investigation of communication disorders: a comparison with monolingual children referred in one area in England. J Multilingual Commun Disord 2005;3:1-23

15. Core C, Hoff E, Rumiche R, Señor M. Total and conceptual vocabulary in Spanish-English bilinguals from 22 to 30 months: implications for assessment. J Speech Lang Hear Res 2013;56(5):1637-1649

16. Hoff E, Core C, Place S, Rumiche R, Señor M, Parra M. Dual language exposure and early bilingual development. J Child Lang 2012;39(1):1-27

17. Thordardottir E, Rothenberg A, Rivard ME, Naves R. Bilingual assessment: can overall proficiency be estimated from separate measurement of two languages? J Multilingual Commun Disord 2006;4:1-21

18. Fabiano-Smith L, Barlow JA. Interaction in bilingual phonological acquisition: evidence from phonetic inventories. Int J Biling Educ Biling 2010; 13(1):81-97 
19. Fabiano-Smith L, Goldstein BA. Phonological acquisition in bilingual Spanish-English speaking children. J Speech Lang Hear Res 2010;53(1):160-178

20. Gildersleeve-Neumann CE, Kester ES, Davis BL, Peña ED. English speech sound development in preschool-aged children from bilingual EnglishSpanish environments. Lang Speech Hear Serv Sch 2008;39(3):314-328

21. Paradis J, Genesee F. Syntactic acquisition in bilingual children. Stud Second Lang Acquis 1996;18:125-181

22. Kehoe M, Trujillo C, Lleó C. Bilingual phonological acquisition: an analysis of syllable structure and VOT. In: Cantone KF, Hinzelin MO, eds. Proceedings of the Colloquium on Structure, Acquisition and Change of Grammars: Phonological and Syntactic Aspects. Universität Hamburg, Germany: Arbeiten zur Mehrsprachigkeit; 2001: 38-54

23. Lleó C, Kuchenbrandt I, Kehoe M, Trujillo C. Syllable final consonants in Spanish and German monolingual and bilingual acquisition. In: Müller $\mathrm{N}$, ed. (In)vulnerable Domains in Multilingualism. Amsterdam, Netherlands, and Philadelphia, PA: John Benjamins; 2003:191-220

24. Goldstein BA, Bunta F. Positive and negative transfer in the phonological systems of bilingual speakers. Int J Biling 2012;16:388-401

25. MacLeod AA, Laukys K, Rvachew S. The impact of bilingual language learning on whole-word complexity and segmental accuracy among children aged 18 and 36 months. Int J Speech-Language Pathol 2011;13(6):490-499

26. Goldstein BA, Fabiano L, Washington PS. Phonological skills in predominantly English-speaking, predominantly Spanish-speaking, and SpanishEnglish bilingual children. Lang Speech Hear Serv Sch 2005;36(3):201-218

27. Goldstein B, Washington PS. An initial investigation of phonological patterns in typically developing 4-year-old Spanish-English bilingual children. Lang Speech Hear Ser 2001;32:153-164

28. Keshavarz MH, Ingram D. The early phonological development of a Farsi-English bilingual child. Int J Biling 2002;6:255-269

29. Gildersleeve C, Davis B, Stubbe E. When monolingual rules don't apply: speech development in a bilingual environment. Paper presented at: American Speech-Language-Hearing Association Convention; November 18-20 2010; Seattle, WA

30. Morrow A, Goldstein BA, Gilhool A, Paradis J. Phonological skills in English language learners. Lang Speech Hear Serv Sch 2014;45(1): 26-39

31. Beckman ME, Edwards J. The ontogeny of phonological categories and the primacy of lexical learning in linguistic development. Child Dev 2000;71(1):240-249
32. Ferguson CA, Farwell CB. Words and sounds in early language acquisition. Language 1975;51(2): 419-439

33. Metsala JL, Walley AC. Spoken vocabulary growth and the segmental restructuring of lexical representations: precursors to phonemic awareness and early reading ability. In: Metsala JL, Ehri LC, eds. Word Recognition in Beginning Literacy. Hillsdale, NJ: Erlbaum; 1998:89-120

34. Pierrehumbert JB. Phonetic diversity, statistical learning, and acquisition of phonology. Lang Speech 2003;46(Pt 2-3):115-154

35. Gathercole SE. Nonword repetition and word learning: the nature of the relationship. Appl Psycholinguist 2006;27:513-543

36. Paul R, Jennings $\mathrm{P}$. Phonological behavior in toddlers with slow expressive language development. J Speech Hear Res 1992;35(1):99-107

37. Rescorla L, Ratner NB. Phonetic profiles of toddlers with specific expressive language impairment (SLI-E). J Speech Hear Res 1996; 39(1):153-165

38. Smith BL, McGregor KK, Demille D. Phonological development in lexically precocious 2-year-olds. Appl Psycholinguist 2006;27(3): 355-375

39. Stoel-Gammon C. Normal and disordered phonology in two-year-olds. Topics in Language Disorder 1991;11(4):21-32

40. Stoel-Gammon C, Dunn C. Normal and Disordered Phonology in Children. Austin, TX: Pro Ed; 1985

41. Conboy BT, Thal DJ. Ties between the lexicon and grammar: cross-sectional and longitudinal studies of bilingual toddlers. Child Dev 2006;77(3): $712-735$

42. Marchman VA, Martínez-Sussmann C, Dale PS. The language-specific nature of grammatical development: evidence from bilingual language learners. Dev Sci 2004;7(2):212-224

43. Dispaldro M, Leonard LB, Deevy P. Clinical markers in Italian-speaking children with and without specific language impairment: a study of non-word and real word repetition as predictors of grammatical ability. Int J Lang Commun Disord 2013;48(5):554-564

44. Goldstein BA, Bunta F, Lange J, Rodriguez J, Burrows L. The effects of measures of language experience and language ability on segmental accuracy in bilingual children. Am J Speech Lang Pathol 2010;19(3):238-247

45. Parra M, Hoff E, Core C. Relations among language exposure, phonological memory, and language development in Spanish-English bilingually developing 2-year-olds. J Exp Child Psychol 2011; 108(1):113-125

46. Core C. Speech production differences in bilingual children with high and low vocabularies. Poster 
presented at: International Child Phonology Conference; June 15-17 2011; University of York, York, UK

47. Core C, Hoff E. Relationships of real and nonword production ability to vocabulary size in Spanish and English speaking toddlers. Paper presented at: International Child Phonology Conference; June 4-6 2012; Minneapolis, MN

48. Scarpelli C, Core C. Predictors of bilingual speech production in English-Spanish speaking preschoolers at 48 months. Poster presented at: Annual Convention of the American Speech-Lan-
guage-Hearing Association; November 20-22 2014; Orlando, FL

49. McLeod S, Verdon S. A review of 30 speech assessments in 19 languages other than English. Am J Speech Lang Pathol 2014;23(4):708-723

50. Peña ED, Gutiérrez-Clellen VF, Iglesias A, Goldstein BA, Bedore LM. BESA: Bilingual EnglishSpanish Assessment. San Rafael, CA: AR-Clinical Publications; 2014

51. Goldstein B, Iglesias A. CPACS: Contextual Probes of Articulation Competence: Spanish. Greenville, SC: Super Duper; 2006 